\title{
Tinnitus and temporomandibular disorders: the knowledge of professionals for primary health care in the city of Curitiba
}

\author{
Paulo Francisco Arant Martins \\ José Stechman-Neto ${ }^{2}$ \\ Jair Mendes Marques ${ }^{3}$ \\ Soriane Kieski Martins ${ }^{4}$ \\ Killian Evandro Cristoff ${ }^{3}$ \\ Rosane Santos Sampaio ${ }^{3}$ \\ Giselle Massi ${ }^{3}$ \\ Wagner Hummig
}

\begin{abstract}
Introduction: The high prevalence of temporomandibular disorders and tinnitus along with the negative effects on the quality of life of affected individuals makes this association a matter of public health. Objective: To assess the knowledge of primary health care professionals about the interrelationship between temporomandibular disorders and tinnitus. Materials and Methods: This was a quantitative cross-sectional study, using a structured, self-administered questionnaire for a group of 54 dental surgeons. The statistical analysis used involved descriptive analyses through absolute and relative frequency distributions. Results: The results showed that the professionals do not, as a routine, examine the temporomandibular joints and masticatory muscles during physical examination. In addition, there was a low percentage of correct answers on questions that assess knowledge. Conclusions: There is a need to inform dentists about the interrelationship between temporomandibular disorders and tinnitus. Furthermore, there is a need to encourage managers to establish teaching and learning tools that support and strengthen the role of dentists in primary health care. In this way, routine visits might minimize these disorders, and thus contribute to the quality of life of the population.
\end{abstract}

Keywords: knowledge, tinnitus, primary health care, facial pain

\footnotetext{
${ }^{1}$ Student the program of Master's in Communication Disorders from University of Paraná Tuiuti and Center for Diagnosis and Treatment of temporomandibular Joint - Tuiuti University, Paraná, PR, Brazil. E-mail: paulof.a.martins@gmail.com

${ }^{2}$ Coordinator of Center for Diagnosis and Treatment of Temporomandibular Joint and Program of Master's and Doctorate in Communication Disorders from the University of Paraná Tuiuti - Tuiuti University, Paraná, Curitiba, PR, Brazil. E-mail: stechman1@gmail.com

${ }^{3}$ Department of master's and doctorate from the University of Paraná Tuiuti - University of Paraná Tuiuti, Curitiba, PR, Brazil. E-mail: jair.marques@utp.br / drkillian@

hotmail.com / rosane.santos2@utp.br / giselle.massi@hotmail.com

${ }^{4}$ Control Center for Municipal Health Department Evaluation and Audil of Curitiba, Curitiba, Brazil. E-mail: sorianekm@gmail.com

${ }^{5}$ Center for Diagnosis and Treatment of Temporomandibular Joint - University of Paraná Tuiuti, Curitiba, PR, Brazil. E-mail: waghum@hotmail.com

Institution: University Tuiuti do Paraná

Send correspondence to:

Paulo Francisco Arant Martins

Avenida Ivo Zanlorenzi, 851 sobrado 06. Curitiba, Paraná, Brazil. CEP 80740-590. E-mail: paulof.a.martins@gmail.com
}

Paper submitted to the RBCMS-SGP (Publishing Management System) on February 16, 2016;

and accepted on March 30, 2016. cod. 223 


\section{INTRODUCTION}

Many patients have subclinical symptoms and specific comorbidities related to temporomandibular disorders (TMD) and otological symptoms, particularly tinnitus. The knowledge of this relationship can reduce the time and costs for public service to meet the population's needs and improve quality of life'.

The high prevalence of this association is a matter of public health, which requires that the professionals involved in the area possess specific knowledge for correct diagnosis, thus aiming to relieve both otological and temporomandibular symptoms ${ }^{2}$.

Pain in the masticatory muscles, pain around the ear, headaches, limited or asymmetrical jaw movement, and temporomandibular joint (TMJ) noise are all commonly reported symptoms of TMD patients, and may be associated with infectious ENT, neurological, vascular, neoplastic diseases in the orofacial region ${ }^{3}$.

The most common ENT symptoms associated with TMD are tinnitus, dizziness, vertigo, ear pain, sense of hearing loss, hyperacusis and ear fullness ${ }^{4,5}$.

According to the American Tinnitus Association (ATA), tinnitus is defined as an experience in which a person hears a sound in the absence of a corresponding acoustic stimulus ${ }^{6}$.

The global incidence of tinnitus is approximately $15 \%$, which means it currently affects 28 million Brazilians $^{7}$. However, the signs and otological symptoms in populations vary between $10-31 \%$, and in the TMD group affect up to $85 \%$ of individuals 8 .

The presence of tinnitus becomes a high-profile factor in an individual's life, making it difficult to sleep, concentrate on daily social and professional activities, achieve emotional balance, thereby worsening states of anxiety and depression ${ }^{9}$.

Research from Barreto et al. ${ }^{10}$, and Pita et al. ${ }^{11}$, in their literature reviews on TMD and its relationship with auditory symptoms, concluded that there is a link between the stomatognathic system and the audio system. Evidence was also observed in TMD causes and consequences covering hearing disorders to muscular and functional alterations.

Researchers have been dedicated to seeking new knowledge on the pathophysiology of otological symptoms in patients with TMD. Wright \& Bifano ${ }^{12}$ outlined five theories described in the literature that attempt to explain the association between TMD and tinnitus.

One of the first scholars in the area was Costen (1934) who studied the clenching and poor positioning of the mandibular condyle and how it could cause compression of auriculotemporal nerves or chorda tympani and the consequent obstruction of the
Eustachian tube. This resulted in symptoms of earache, tinnitus, hearing loss and ear fullness, and that the pressure of the condyle could cause blockage in the Eustachian tube, thus producing tinnitus.

The second theory was based on the common innervation of the masticatory muscles and the tensor muscle of the soft palate and the tensor tympani. The hyperactivity of masticatory muscles could induce a secondary reflex contraction of the tensor muscle of the soft palate, which results in a poor opening of the Eustachian tube, causing ear fullness in the middle ear. Following the same theory, trigeminal nerve stimulation causes secondary reflex contraction of the tensor tympani muscle, which can cause tinnitus.

Another theory with a neurological basis is the assumption that the middle and inner ears receive trigeminal nerve and sympathetic system stimulation through the tympanic plexus of the middle ear, and that these stimulus combinations can explain tinnitus.

The fourth theory suggests that release of neuromodulators in intra-articular inflammatory processes in the TMJ can affect the middle and inner ears and produce tinnitus.

Some studies are based on the structural link between the TMJ and the middle ear, describing how the sphenomandibular ligament passes through the petrotympanic fissure to the hammer. Pinto (1962) reported that moving the TMJ causes movement in the ossicle chain in the middle ear and the tympanic membrane.

Multifactorial diversity can lead to TMD, making it difficult to identify a single cause for the presence of ear complaints in a population with TMD ${ }^{13}$.

In this context, the aim of this study is to verify the knowledge of primary health dentists about the interrelationship of temporomandibular disorders and tinnitus.

Therefore, the justification for the choice of this subject is the need to conduct studies that show the importance of linking auditory symptoms and TMD, emphasizing the integral work of health professionals, and, therefore, a correct diagnosis in order to reduce costs for public health services and, especially, to improve the quality of life for the population ${ }^{1,10}$.

\section{METHODS}

The Municipal Health Secretariat in the city of Curitiba has 396 dental surgeons (DS) working in primary care. For this study 54 professionals were randomly selected from the nine health districts $(n=$ 54). A questionnaire was used for this quantitative crosssectional study between the November and December, 2014, after approval by the Research Ethics Committee at the Hospital Universitário Evangélico de Curitiba under 
number 777.519 and the technical feasibility approval by the Research Ethics Committee of the Curitiba Municipal Health Secretariat under number 797.186.

Inclusion criteria were: DS working in primary care in the city of Curitiba, who were active, and agreed to participate. The exclusion criterion was limited only to those who did not agree to participate.

The tool used for the study was a structured, three-part, self-administered questionnaire with closedended questions. The first part of the questionnaire was to identify the DS and obtain general professional data. The second part consisted of questions checking the DS knowledge about the interrelation of TMD and tinnitus. While the third part included questions to determine the TMD and tinnitus recognition and referrals for primary health care in Curitiba.

This research tool was applied to a pilot group composed of five primary care DS to validate the questionnaire. Suggestions for changes were analyzed and the survey tool altered.

The statistical analysis used descriptive analysis involved through distribution of relative and absolute frequencies and average values.

This research will promote benefits to managers, professionals and patients, as the results may generate actions and interventions. There was no risk involved in carrying out the research.

\section{RESULTS}

The results of the data collection process showed that 42 of the DS $(70.37 \%)$ were women and the average age was 45.4 years - minimum of 26 , maximum of 62 , with a standard deviation of 8.7 years.

In Table 1 it can be seen that 41 (75.93\%) professionals "sometimes" assess the TMJ and masticatory muscles during a clinical examination of the patient and $4(7.41 \%)$ do not evaluate these structures at all.

Table 2 refers to questions that assess knowledge on the subject. Question 5 focuses on the relationship between occlusion and TMD and only 1 DS (1.85\%) answered correctly, while questions 4,8 , and 9 were answered correctly over $80 \%$ of the time.

As for the answers to questions that assess knowledge of the interrelationship between the TMD and tinnitus, Table 3 shows that the percentage of correct answers was $50.26 \%$ or an average of 27.1 correct answers.

By analyzing the responses regarding conduct with TMD patients in Table 4, it was found that 17 DS (31.48\%) treat it, 16 DS (29.63\%) refer patients to another professional, and others do not treat or refer patients, or did not answer the question.
Table 1. Evaluation.

\begin{tabular}{lccc}
\hline ANSWERS & & FREQUENCY & $\%$ \\
\hline Q1 - Evaluation of & Yes & 9 & $16.67 \%$ \\
TMJ and masticatory & No & 4 & $7.41 \%$ \\
muscles during & Sometimes & 41 & $75.93 \%$ \\
clinical exam & TOTAL & 54 & $100.00 \%$ \\
\hline
\end{tabular}

Source: Authors, 2014. TMJ = Temporomandibular joint

Table 2. Sample distribution concerning knowledge in questions 3 through 9.

\begin{tabular}{|c|c|c|c|c|}
\hline \multirow[b]{2}{*}{ QUESTION } & \multicolumn{4}{|c|}{ RESULTS } \\
\hline & Correct & Incorrect & $\begin{array}{l}\text { Don't } \\
\text { know }\end{array}$ & $\begin{array}{c}\text { No } \\
\text { answer }\end{array}$ \\
\hline $\begin{array}{l}\text { Q3- The most } \\
\text { common clinical } \\
\text { manifestation is } \\
\text { TMJ pain }\end{array}$ & $\begin{array}{c}24 \\
(44.44 \%)\end{array}$ & $\begin{array}{c}27 \\
(50.00 \%)\end{array}$ & $\begin{array}{c}1 \\
(1.85 \%)\end{array}$ & $\begin{array}{c}2 \\
(3.70 \%)\end{array}$ \\
\hline $\begin{array}{l}\text { Q4- Relationship } \\
\text { between TMD and } \\
\text { tinnitus }\end{array}$ & $\begin{array}{c}47 \\
(87.04 \%)\end{array}$ & - $(0.00 \%)$ & $\begin{array}{c}7 \\
(12.96 \%)\end{array}$ & $\begin{array}{c}- \\
(0.00 \%)\end{array}$ \\
\hline $\begin{array}{l}\text { Q5- Relationship } \\
\text { between TMD and } \\
\text { occlusion }\end{array}$ & $1(1.85 \%)$ & $\begin{array}{c}52 \\
(96.30 \%)\end{array}$ & - $(0.00 \%)$ & $\begin{array}{c}1 \\
(1.85 \%)\end{array}$ \\
\hline $\begin{array}{l}\text { Q6- Relationship } \\
\text { between tinnitus } \\
\text { and occlusion }\end{array}$ & $4(7.41 \%)$ & $\begin{array}{c}30 \\
(55.56 \%)\end{array}$ & $\begin{array}{c}19 \\
(35.19 \%)\end{array}$ & $\begin{array}{c}1 \\
(1.85 \%)\end{array}$ \\
\hline $\begin{array}{l}\text { Q7- Occlusion may } \\
\text { be principal cause } \\
\text { of TMD }\end{array}$ & $\begin{array}{c}22 \\
(40.74 \%)\end{array}$ & $\begin{array}{c}29 \\
(53.70 \%)\end{array}$ & $\begin{array}{c}2 \\
(3.70 \%)\end{array}$ & $\begin{array}{c}1 \\
(1.85 \%)\end{array}$ \\
\hline $\begin{array}{l}\text { Q8- Bruxism is } \\
\text { significant in the } \\
\text { development of TMJ }\end{array}$ & $\begin{array}{c}44 \\
(81.48 \%)\end{array}$ & $\begin{array}{c}6 \\
(11.11 \%)\end{array}$ & $\begin{array}{c}4 \\
(7.41 \%)\end{array}$ & $\begin{array}{c}- \\
(0.00 \%)\end{array}$ \\
\hline $\begin{array}{l}\text { Q9- Stress is } \\
\text { a factor in the } \\
\text { development of } \\
\text { TMJ and tinnitus }\end{array}$ & $\begin{array}{c}48 \\
(88.89 \%)\end{array}$ & - $(0.00 \%)$ & $\begin{array}{c}4 \\
(7.41 \%)\end{array}$ & $\begin{array}{c}2 \\
(3.70 \%)\end{array}$ \\
\hline \multicolumn{5}{|c|}{$\begin{array}{l}\text { Source: Authors, 2014. TMJ = Temporomandibular joint; TMD = } \\
\text { Temporomandibular disorder } \\
\text { Table 3. Percentages and average values for answers for } \\
\text { questions regarding knowledge on the association between } \\
\text { TMD and tinnitus. }\end{array}$} \\
\hline ANSWERS & \multicolumn{2}{|c|}{$\%$} & \multicolumn{2}{|c|}{ AVERAGE VALUES } \\
\hline Correct & \multicolumn{2}{|c|}{$50.26 \%$} & \multicolumn{2}{|c|}{27.1} \\
\hline Incorrect & \multicolumn{2}{|c|}{$38.10 \%$} & \multicolumn{2}{|c|}{20.6} \\
\hline Don't know & \multicolumn{2}{|c|}{$9.79 \%$} & \multicolumn{2}{|c|}{5.3} \\
\hline No Answer & \multicolumn{2}{|c|}{$1.85 \%$} & \multicolumn{2}{|c|}{1.0} \\
\hline TOTAL & \multicolumn{2}{|c|}{$100.00 \%$} & & \\
\hline
\end{tabular}

Source: Authors, 2014

When asked for the reasons that the DS do not treat patients with TMD and tinnitus, Table 4 shows that 30 DS $(55.5 \%)$ responded that they lack knowledge and $23(42.59 \%)$ did not answer the question. 
Table 4. Information on knowledge and conduct.

\begin{tabular}{lcc}
\hline QUESTION & FREQUENCY & $\%$ \\
\hline Q10 - Conduct with TMD patients & 17 & $31.48 \%$ \\
Treat & 16 & $29.63 \%$ \\
Refer to other health professional & 1 & $5.55 \%$ \\
No referral & 6 & $11.11 \%$ \\
No treatment & 12 & $22.22 \%$ \\
No answer & 54 & $100.00 \%$ \\
TOTAL & & $55.5 \%$ \\
\hline Q11 - Reasons for non-treatment & 30 & $1.85 \%$ \\
\hline Insufficient knowledge and lack of material & 1 & $42.59 \%$ \\
No established procedure & 23 & \\
No answer & & $86.95 \%$ \\
\hline Q12 - Effective methods of treatment & & $1.85 \%$ \\
\hline $\begin{array}{l}\text { Occlusal adjustment, orthodontics, IOD, acupuncture, } \\
\text { Oral and maxillofacial surgery, physiotherapy, drug } \\
\text { therapy } \\
\text { IOD, acupuncture, drug therapy }\end{array}$ & 47 & $100 \%$ \\
No answer & 6 & 1 \\
TOTAL & 54 & \\
\hline
\end{tabular}

Source: Authors, 2014. IOD: intraoral devices; TMD: Temporomandibular disorder

The results presented in Table 4 show that the method considered most effective by DS to treat TMD was occlusal adjustment, orthodontics and oral and maxillofacial surgery, orthodontics, intraoral devices (IOD), acupuncture and physiotherapy, with 47 (86.95\%) pointing to these as effective treatments.

It should be noted that among the answer choices were not to answer it or leave the answer blank. Therefore the three questions that make up the data from Table 4 had some unanswered questions.

\section{DISCUSSION}

This research analyzes the knowledge of primary health care professionals about the interrelationship of temporomandibular disorders and tinnitus. It was found that the average DS does not routinely examine the TMJ and masticatory muscles during clinical examination. Such a procedure can diagnose conditions such as $T M D$, tinnitus and their association.

According to Leeuw ${ }^{3}$, assessment of TMD and orofacial disorders during clinical examinations is an integral part of the dental practice.

To carry out the practice based on complete assistance, the professional can improve results and include the principles and guidelines of the Brazilian Unified Health System (SUS), which understands the completeness of assistance, such as "articulate and continuous sets of actions and preventive services and treatments, both individual and collective, required for each case in all levels of complexity of the system." ${ }^{14}$.
Patients with TMD have some similar characteristics to each other, requiring a differential diagnosis with respect to diseases that have similar manifestations and symptoms. Therefore, a proper history and physical examination are essential because there is the risk of inappropriate treatment resulting in the worsening of symptoms ${ }^{15}$.

Dysfunctions of the TMJ are important causes of morbidity in the general population, making it the most relevant cause of otological symptoms ${ }^{16}$.

Buergers et al. found a prevalence of tinnitus that was eight times higher in the TMD group (30 of 82 [36.6\%]) than in the group without TMD (38 of 869 [4.4\%]), all participants with TMD and unilateral tinnitus with both symptoms of the same side, predominantly female and concluded that there is significant correlation between tinnitus and TMD ${ }^{17}$.

The fact that the DS does not conduct routine clinical examination to identify TMD/tinnitus interferes with treatment, given the significant number of professionals who do not deal with the problem or did not answer the question about the conduct with these patients.

When considering that many patients have subclinical symptoms and specific comorbidities related to TMD and tinnitus, along with the high prevalence of this association in this matter of public health, specific knowledge is necessary for the proper diagnosis of these problems $^{1,2}$.

The data analysis emphasizes that professionals are unaware of the relationship between occlusion and 
TMD/ tinnitus. There are studies that point to a lack of association in the relationship between occlusion and TMD. During the training process there is still a theory in some educational institutions that TMD is simply a problem of occlusion. Occlusion is a broad term with many variables, so we find fewer and fewer scientific articles discussing the relationship between occlusion and TMD, because the main focus is on the TMJ'18,19.

According to Sartoretto et al. ${ }^{19}$, although these remain controversial issues, scientific evidence does not seem to support the orthodontic-TMD relationship, as well as the relationship with occlusion.

This study confirmed the substantial absence of clinically significant effects of orthodontics regarding the cause of $\mathrm{TMD}^{20}$.

The results pointed to a relatively low level of knowledge of the issues assessed about the interrelationship between TMD and tinnitus.

It is noteworthy that we did not find any other work in the field of knowledge with these characteristics or assessing the knowledge of primary health care DS regarding TMD/ tinnitus. However, this study corroborates the results found in a study on the assessment of knowledge of medical students about brain death, in which the low level of knowledge was due, in part, to the limited contact that students have with the topic during schooling and the low importance placed on the topic by teaching institutions ${ }^{21}$.

There are still many doubts on the subject, mainly because it is a new concept, not yet widespread in the general population, and therefore it has not been prioritized in undergraduate and postgraduate schooling ${ }^{21}$.

It was noted that the number of DS who treat patients with TMD/ tinnitus is low, given the prevalence of this disorder. This fact is probably due to insufficient knowledge to carry out such treatment.

With regard to the most effective methods in treating TMD, the objective was to verify the knowledge between reversible and irreversible methods, but the question was not clear. Still, the trend of using irreversible methods such as occlusal adjustment, orthodontics and maxillofacial surgery was identified.

Therapies that combine occlusal splints with other therapies were more effective in order to improve the otological symptoms associated with TMD. It can be said that combination therapy deserves more consideration ${ }^{22}$. The use of occlusal splints focuses on their non-invasive and reversible nature, i.e., there is a change of the patient's condition and occlusal dimensions providing a more physiological and functional position without the need for more invasive and irreversible procedures such as orthodontic treatment, occlusal adjustment, or surgery ${ }^{13,23}$.
Limiting factors of this study were sample size, clarity in the questions on the knowledge between reversible and irreversible methods, and descriptive analysis.

The absence of studies that assess the knowledge of the primary health care DS on TMD/ tinnitus in the literature is highlighted - a relevant factor for further research and especially to address the issue with health professionals, helping them to expand the resoluteness of their actions, considering the current needs of the population.

\section{CONCLUSION}

The data presented in this study indicate that DS working in primary health care in the city of Curitiba need to expand their knowledge about TMD and tinnitus, and thus realize the importance of proper clinical examinations in order to include the examination of TMJ and masticatory muscles allowing for a correct diagnosis and appropriate approach to the situation presented.

It is imperative to note that the situation has already been recognized as a public health problem, so managers should be alerted to the need to equip their professionals working in primary health care, as well as support planning at all levels of care that include actions to solve these problems for patients in their care.

It is suggested that continuing education can be a strategy to show the professional the need to broaden their knowledge in a given area, because changes in perception, and consequently in practice, are ways to offer solutions and more comprehensive care.

\section{REFERENCES}

1. Pascoal MIN, Rapoport A, Chagas JFS, Pascoal MBN, Costa CC Magna LA. Prevalência dos sintomas otológicos na desordem temperomandibular: estudo de 126 casos. Rev Bras Otorrinolaringol. 2001;67(5 pt 1):627-33. DOI: http://dx.doi.org/10.1590/S003472992001000500005

2. Vielsmeier V, Strutz J, Kleinjung T Schecklmann M, Kreuzer PM, Landgrebe $\mathrm{M}$, et al. Temporomandibular joint disorder complaints in tinnitus: further hints for a putative tinnitus subtype. PLoS One. 2012;7(6):e38887.

3. Leeuw R. Dor orofacial: guia de avaliação, diagnóstico e tratamento. 4ªed. São Paulo: Quintessence; 2010.

4. Jacob LCB, Rabiço TM, Campêlo RM, Aguiar FP, Zeigelboim BS. Sintomas auditivos e análise das emissões otoacústicas evocadas por estímulo transiente em indivíduos portadores de disfunção temporomandibular. Distúrb Comun. 2005;17(2):173-82.

5. Tuz HH, Onder EM, Kisnisci RS. Prevalence of otologic complaints in patients with temporomandibular disorder. Am J Orthod Dentofacial Orthop. 2003;123(6):620-3. PMID: 12806339

6. ATA - Information about American Tinnitus Association. Portland, 2011. [cited 2014 Jun 8]. Available from: http://www.ata.org/forpatients/about-tinnitus\#what\%20is\%20tin\%C2\%ACnitus

7. Siqueira JTT, Teixeira MJ, orgs. Dores orofaciais: diagnóstico e tratamento. Porto Alegre: Artes Médicas; 2012.

8. Salvetti G, Manfredini D, Barsotti S, Bosco M. Otologic symptoms in temporomandibular disorders patients: is there evidence of an association-relationship? Minerva Stomatol. 2006; 55(11-12):627-37. 
9. Fernandes G, Siqueira JT, Godoi Gonçalves DA, Camparis MC Association between painful temporomandibular disorders, sleep bruxism and tinnitus. Braz Oral Res. 2014; 28 pii: S180683242014000100220.

10. Barreto DC, Barbosa ARC, Frizzo ACF. Relação entre disfunção temporomandibular e alterações auditivas. Rev CEFAC. 2010;12(6):1067-76.

11. Pita MS, Ribeiro AB, Zuim PRJ, Garcia AR. Hearing symptoms and temporomandibular disorders. Rev Odont Araçatuba, 2010;31(1):3845.

12. Wright EF, Bifano SL. Tinnitus improvement through TMD therapy. J Am Dent Assoc. 1997;128(10):1424-32. PMID: 9332144

13. Nichthauser B, Andrade e Silva F, Buarque e Silva WA, Rodrigues MFR, Buarque e Silva LL, Moura LG. Sintomas otológicos em pacientes com disfunção temporomandibular tratados com aparelhos oclusais lisos e planos. Rev Port Estomatol Cir Maxilofac. 2012;53(4):213-20.

14. Brasil. Lei 8.080 , de 19 de setembro de 1990. Dispõe sobre as condições para promoção, proteção e recuperação da saúde, a organização e o funcionamento dos serviços correspondentes e dá outras providências. Diário Oficial da União, Brasília, DF, 20 set. 1990. p.18055. [cited 2015 Mar 18]. Available from: http://www.planalto. gov.br/ccivil_03/Leis/L8080.htm

15. Piozzi R, Lopes FC. Temporomandibular disorders: clinical aspects and a guideline to odontology and physiotherapy. J Bras Oclus ATM Dor Orof. 2002;2(5):43-7.
16. Okeson JP. Tratamento das desordens temporomandibulares e oclusão. 6a ed. Rio de Janeiro: Elsevier; 2008.

17. Buergers $R$, Kleinjung $T$, Behr $M$, Vielsmeier $V$. Is there a link between tinnitus and temporomandibular disorders? J Prosthet Dent. 2014;111(3):222-7.

18. Bósio JA. O paradigma da relação entre oclusão, ortodontia e disfunção têmporo-mandibular. Rev Dent Press Ortodon Ortop Facial. 2004;9(6):84-9.

19. Sartoretto SC, Dal Bello Y, Della Bona A. Scientific evidence for the diagnosis and treatment of MD and its relation to occlusion and orthodontics. Rev Fac Odontol UPF. 2012;17(3):352-9.

20. Manfredini D, Stellini E, Gracco A, Lombardo L, Nardini LG, Siciliani G. Orthodontics is temporomandibular disorder-neutral. Angle Orthod. 2015. Oct 29. [Epub ahead of print].

21. Bitencourt AGV, Neves FBCS, Durães L, Nascimento DT, Neves NMBC, Torreão LA, et al. Avaliação do conhecimento de estudantes de medicina sobre morte encefálica. Rev Bras Ter Intensiva. 2007;19(2):144-50.

22. Stechman-Neto J, Porporatti AL, Porto de Toledo I, Costa YM, Cont PC, De Luca Canto G, et al. Effect of temporomandibular disorder therapy on otologic signs and symptoms: a systematic review. $J$ Oral Rehabil. 2016 Jan 8. doi: 10.1111/joor.12380. [Epub ahead of print]

23. Uemoto L, Macedo MEG, Alfaya TA, Souza FN, Barcelos R, Gouvêa CVD. Impact of supportive therapy for otological changes in patients with temporomandibular joint disorders. Rev Dor. 2012;13(3):208-12. 